\title{
SEPARATION AND DETERMINATION OF THE R-ISOMER OF ETODOLAC IN A BULK DRUG SUBSTANCE BY NORMAL-PHASE LIQUID CHROMATOGRAPHY
}

\author{
APPASAHEB B LAWANDE \\ Department of Chemistry, Shri Jagdish Prasad Jhabarmal Tibrewala University, Vidyanagari, Jhunjhunu, Rajasthan, India. \\ Email: ab.lawande@rediffmail.com
}

Received: 09 August 2016, Revised and Accepted: 16 August 2016

\section{ABSTRACT}

Objective: The objective of this work was to develop and validate a novel, simple, rapid, and reliable analytical method for separation and determination of R-isomer impurity in Etodolac bulk drug material by normal-phase high-performance liquid chromatography (HPLC) as per International Conference on Harmonization (ICH) guidelines.

Methods: The etodolac R-isomer and S-isomer were separated on a Chiralcel OD-H (150 × $4.0 \mathrm{~mm}, 5 \mu \mathrm{m})$ column using ethanol: $\mathrm{n}$-hexane: Trifluoroacetic acid (50:50:0.1 v/v.) mobile phase with equipped detector at wavelength $225 \mathrm{~nm}$ and $25^{\circ} \mathrm{C}$ column oven temperature. The resolution between R-isomer and S-isomer was more than two recorded on the chromatogram. The specified method was developed and validated for various parameters such as reproducibility, limit of detection (LOD), limit of quantification, linearity and range, robustness, solution stability and mobile phase stability according to the ICH guidelines.

Results: Linearity was found for etodolac R-isomer over the concentration range of 600-6000 ng/ml, with the linear regression (correlation coefficient $\mathrm{R}=0.998$ ) and proved to be robust. LOD and limit of quantification of etodolac R-isomer were found to be 200 and $600 \mathrm{ng} / \mathrm{ml}$. The retention time of R-isomer was considered to be 2.8 minutes. The percentage recovery of etodolac R-isomer has been ranged from 97.0 to 102.0 in bulk drug material sample. The proposed analytical method has been found to be suitable, precise, reliable and accurate for the separation and quantitative determination of etodolac R-isomer in bulk drug sample.

Conclusion: A novel, speedy, accurate, precise, reliable and rugged analytical method have been developed and validated for normal phase HPLC to determine R-isomer impurity in etodolac bulk drugs material as per ICH guideline.

Keywords: Etodolac, High performance liquid chromatography, Known impurity, Normal phase, Validation.

(C) 2016 The Authors. Published by Innovare Academic Sciences Pvt Ltd. This is an open access article under the CC BY license (http://creativecommons. org/licenses/by/4. 0/) DOI: http://dx.doi.org/10.22159/ajpcr.2016.v9i6.14597

\section{INTRODUCTION}

Etodolac is used in the treat pain. Etodolac is active pharmaceutical bulk drug used in manufacturing of tablet and capsules. It works by reducing hormones that cause inflammation and mild to moderate pain in the body. In addition to this, it maintains a better physiological regulation for secretion of insulin. Etodolac is a racemic mixture of R-isomer and S-isomer

Various types of analytical methods have been reported for qualitative and quantitative analysis of etodolac. In the literature enantiomeric separation of etodolac by reverse phase chromatography [1], nonsteroidal anti-inflammatory drug analysis [2], etodolac efficient method for optical resolution [3], bioequivalence of S-etodolac determination [4], and optical resolution of the drug by capillary electrophoretic techniques [5]. This report describes a normal phase liquid chromatography method for the speedy separation of R-isomer and S-isomer of etodolac. The developed high-performance liquid chromatography (HPLC) method has been validated for quantitative determination of R-isomer in etodolac. Etodolac is racemic mixture of $(+) \mathrm{S}$ and $(-) \mathrm{R}$-etodolac. Etodolac chemically known as 1,8-diethyl-1,3,4,9-tetrahydropyrano [3,4-b]indole1-acetic acid, chemical structures show in Fig. 1. (R)-(-)-etodolac show in Fig. 2 and (S)-(+)-etodolac show in Fig. 3.

\section{METHODS}

\section{Chemicals and reagents}

Etodolac, etodolac racemic of R-isomer and S-isomer were kindly supplied by Lavender Laboratories Private Limited, Kurkumbh, Pune, Maharashtra, India. All the reagents were used of HPLC grade, n-hexane purchased from Merck, absolute ethanol purchased from Hayman speciality products UK and trifluoroacetic acid purchased from SigmaAldrich.

\section{Instrument specification}

LC system of Shimadzu 2010 series with ultraviolet (UV) detector and inbuilt auto injector was utilized for method development and validation. The data acquisition and system suitability calculation trigger using LC solution software. Analytical balance used for weighing, electronic balance type 200 Shimadzu corporation Japan. The instrument also consists of Chiralcel OD-H column $(150 \times 4.0 \mathrm{~mm}, 5 \mu \mathrm{m})$.

\section{Chromatographic conditions}

Mobile phase (v/v): Ethanol: n-hexane: Trifluoroacetic acid (50:50:0.1). Column: Chiralcel OD-H $(150 \times 4.0 \mathrm{~mm}, 5 \mu \mathrm{m})$. Flow rate was set at $1.0 \mathrm{ml} /$ minutes. The column oven temperature was maintained at $25^{\circ} \mathrm{C}$. UV detection was carried out at a wavelength of $225 \mathrm{~nm}$. The injection volume was $5 \mu \mathrm{l}$. The mobile phase was filtered through a $0.25 \mathrm{~mm}$ membrane filter and degassed to remove dissolved gases if any.

\section{Preparation of stock solution and sample solution}

Racemic etodolac stock solutions $(0.1 \mathrm{mg} / \mathrm{ml})$ were prepared by dissolving in the mobile phase of an appropriate amount of the substances. The working solutions of etodolac S-isomer and R-isomer were prepared in mobile phase of an analyte concentration of S-isomer was fixed as $0.1 \mathrm{mg} / \mathrm{ml}$.

\section{Validation of developed method Method reproducibility}

Developed method was determined by has been reproduced and measuring repeatability by instrument precision and method precision. 


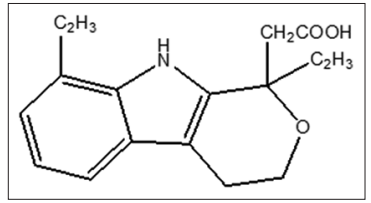

Fig. 1: Chemical structure: 2-(1,8-diethyl-4,9-dihydro-3Hpyrano[3,4-b]indol-1-yl)acetic acid

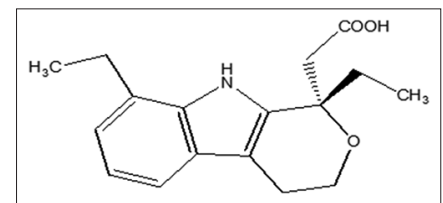

Fig. 2: Chemical structure: (R)-(-)-etodolac

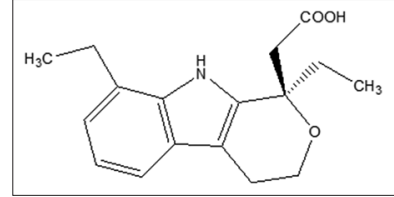

Fig. 3: Chemical structure: (S)-(+)-etodolac

The intermediate precision performed on different days for retention times and peak areas response of R-isomer and S-isomer.

The instrument precision determined on six replicate injections of racemic mixture of etodolac. Method repeatability determined on six sample injections of a $0.1 \mathrm{mg} / \mathrm{ml}$ concentration solution containing R-isomer spiked in S-isomer (i.e., of 0.5\%) was carried out. Intermediate precision was also determined on over a period of day by carrying successive six replicate injections per day.

\section{Limit of detection (LOD) and limit of quantification of R-isomer}

The LOD, defined as the lowest concentration of analyte that can be accepted at detection level on above the baseline signal and not required to quantified, the signal was estimated above the baseline as three times the signal to noise ratio [6].

The limit of quantitation (LOQ), defined as lowest concentration of analyte that can be quantified, reproducible with suitable precision and accuracy, the signal was estimated as ten times the signal to noise ratio [6]. The LOD and LOQ were achieved by injecting a series of dilute solutions of R-isomer.

The developed method has been precise, reliable for determination of R-isomer of etodolac at limit of quantification level was checked by testing with six test solutions of R-isomer etodolac, which was prepared at LOQ level and percentage relative standard deviation (\% RSD) calculated for area response.

\section{Linearity and range of R-isomer}

Linearity for detector response was assessed by on six calibration of sample solutions preparation of R-isomer covering range from $600 \mathrm{ng} / \mathrm{ml}$ (LOQ) to $3000 \mathrm{ng} / \mathrm{ml}(600 \mathrm{ng} / \mathrm{ml}, 1200 \mathrm{ng} / \mathrm{ml}, 1800 \mathrm{ng} / \mathrm{ml}$ $2400 \mathrm{ng} / \mathrm{ml}, 3000 \mathrm{ng} / \mathrm{ml}$ and $6000 \mathrm{ng} / \mathrm{ml}$ ), solution was prepared in mobile phase from R-isomer stock solution.

Obtained regression curve was by plotting peak area response against concentration of solution using the least squares method. Linearity was performed on three consecutive days of same concentration range from the same stock solution. The relative standard deviation in percentage of the slope and Y-intercept of the calibration curve was calculated. Quantification of R-isomer in bulk sample.
The sample of etodolac was supplied by Lavender Laboratories Private Limited showed the presence of R-isomer is $0.10 \%$. Recovery experiments and standard addition were conducted to determine the accuracy of the present method for the quantification of R-isomer in etodolac bulk drug samples.

The study was carried out in triplicate at $0.25,0.50$ and $0.75 \%$ of targeted analyte concentration of etodolac. The calculated recovery of etodolac R-isomer was obtained by calibration curve from the slope and Y-intercept.

\section{Robustness}

The method robustness of an ability of the method to remain unaffected by small change in method parameters, i.e., column oven temperature, flow rate, composition of mobile phase. To determine the method robustness by experimental conditions were purposely altered and checked chromatographic resolution between R-isomer and S-isomer of etodolac was evaluated.

The flow rate of mobile phase was $1.0 \mathrm{ml} /$ minutes. To study the impact of flow rate on the resolution of isomers, it was changed from $0.8 \mathrm{ml} /$ minutes to $1.2 \mathrm{ml} /$ minutes by $\pm 0.2 \mathrm{ml} /$ minutes. The effects of change in the proportion of ethanol on resolution were studied by varying from $-1 \%$ to $+1 \%$ and other components of mobile phase were held constant as stated in section 2.4. The effect of column oven temperature on resolution was changing at $20^{\circ} \mathrm{C}$ and $30^{\circ} \mathrm{C}$ instead of $25^{\circ} \mathrm{C}$. While the mobile phase components and flow rate were held constant as stated.

\section{Solution stability and mobile phase stability}

Solution stability of etodolac in solution form of an analyte concentration was studied by keeping tightly closed volumetric flask at room temperature on work bench in laboratory for $48 \mathrm{hrs}$. The content of etodolac R-isomer was checked for every 6 hrs time interval up to the study period.

The stability of mobile phase was carried out by evaluating the content of etodolac R-isomer in sample solutions. Freshly prepared samples were injected at every $6 \mathrm{hrs}$ time interval for $48 \mathrm{hrs}$. Same mobile phase was used for both of the experiment during the study period.

\section{Specificity and system suitability}

The ability to well separate and measure accurately of R-isomer of etodolac, specifically in etodolac recemic solution and analyte peak of a sample solution. Checked the interference of the blank, standards solution with interest of an analyte and test preparation. No interference observed corresponding to the analyte peak of a sample solution.

\section{Calculations}

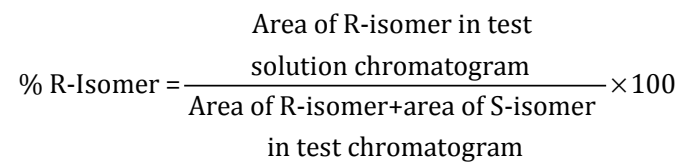

\section{RESULTS AND DISCUSSION}

\section{A method development}

The aim of the work is a separation and determination of R-isomer and S-isomer of etodolac using normal phase HPLC within a very short run time. The etodolac chiral analysis is time-consuming by using normal phase. The $0.1 \mathrm{mg} / \mathrm{ml}$ solution concentration of recemic mixture prepared in mobile phase, which was used for the method development. To develop a rugged, precise and suitable LC method for the separation of etodolac isomer, different mobile phases, and stationary phases were employed. In an experiment has been an attempt to separate the isomers of etodolac. Various experiments were conducted, to select the best stationary and mobile phases that would give suitable resolution and selectivity for the two isomers from recemic mixture. There is 
no method in literature using mobile phase composition of ethanol: N-hexane: Trifluoroacetic acid (50:50:0.1 v/v) by using Chiralcel OD-H column. The chromatographic separation was achieved on a Chiralcel OD-H $(150 \times 4.0 \mathrm{~mm}, 5 \mu \mathrm{m})$ column using a mobile phase system containing ethanol: N-hexane: Trifluoroacetic acid (50:50:0.1 v/v).

The flow rate of the mobile phase was $1.0 \mathrm{ml} /$ minutes. At $25^{\circ} \mathrm{C}$ column temperature, the peak shape of etodolac was found symmetrical.

In the developed and validated optimized method, the typical retention times of R-isomer and S-isomer of etodolac were about 2.8 and 3.5 minutes, respectively. The isomeric separation of etodolac is shown in Fig. 4. The system suitability test results are tabulated as below presented in Table 1

Table 1: Systemsuitability parameters and report

\begin{tabular}{lll}
\hline S. No. & Parameter & Results \\
\hline 1 & Retention time of R-isomer & 2.8 minutes \\
2 & Retention time of S-isomer & 3.5 minutes \\
3 & Resolution (USP) & 2.4 \\
4 & *Number of therotical plates of R-isomer & 4310 \\
5 & *Number of therotical plates of S-isomer & 4415 \\
6 & Tailing factor (USP) of R-isomer & 1.2 \\
7 & Tailing factor (USP) of S-isomer & 1.1 \\
\hline
\end{tabular}

*Calculated on USP tangent method

Table 2: Validation results of the developed normal phase method

\begin{tabular}{lll}
\hline S. No. & Validation parameter & Results \\
\hline $\begin{array}{l}\text { A. Repeatability } \\
\text { (n=6, \% RSD) }\end{array}$ & \\
1 & & \\
2 & Retention time of R-isomer & 0.4 \\
3 & Retention time of S-isomer & 0.6 \\
4 & Peak area of R-isomer & 3.1 \\
B. Intermediate pricision & Peak area of S-isomer & 0.7 \\
(n=18, \% RSD) & & \\
1 & Retention time of R-isomer & 0.8 \\
2 & Retention time of S-isomer & 0.5 \\
3 & Peak area of R-isomer & 3.2 \\
4 & Peak area of S-isomer & 0.8 \\
C. LOD-LOQ (R-isomer) & & \\
1 & LOD (ng/ml) & 200 \\
2 & LOQ (ng/ml) & 600 \\
3 & Precision at LOQ (\% RSD) & 2.9 \\
D. Linearity (R-isomer) & & \\
1 & Calibration range (ng/ml) & $600-6000$ \\
2 & Calibration points & 6 \\
3 & Correlation coefficient & 0.998 \\
\hline
\end{tabular}

\% RSD: Percentage relative standard deviation, LOD: Limit of detection, LOQ: Limit of quantification

\section{Validation results of the method}

The $\%$ RSD was better than $0.7 \%$ for the retention times of the isomers, $0.9 \%$ for etodolac peak area and $4.0 \%$ for R-isomer peak area presented in Table 2. In the intermediate precision study, results show that values of \% RSD were in the same manner obtained for repeatability and presented in Table 2 .

The LOD and LOQ concentrations were determined to be 200 and $600 \mathrm{ng} / \mathrm{ml}$ for R-isomer of etodolac when a signal-to-noise ratio of 3 for detection and 10 for quantitation were used as the criteria. The method precision for R-isomer of etodolac at the limit of quantification was $<4 \%$ RSD presented in Table 2 .

Good linearity was observed for R-isomer of etodolac over the concentration range of 600-6000 $\mathrm{ng} / \mathrm{ml}$. Linearity was checked for R-isomer of etodolac over the same concentration range for 3 consecutive days. The \% RSD for the calibration curve of the slope and Y-intercept were 2.2 and 1.4, respectively, presented in Table 2.

The recovery experiments and standard addition were conducted for R-isomer of etodolac in bulk samples in triplicate at $0.25,0.50$ and $0.75 \%$ of analyte concentration. Recovery was calculated for the calibration curve from slope and Y-intercept obtained in linearity study

Table 3: Recovery results of R-isomer in bulk drugs

\begin{tabular}{llll}
\hline Added (ng) (n=3) & Recovered (ng) & \% Recovery & \% RSD \\
\hline 1003 & 977 & 97.4 & 2.8 \\
2520 & 2570 & 102.0 & 2.1 \\
3941 & 3917 & 99.4 & 2.0 \\
\hline
\end{tabular}

Table 4: Method robustness

\begin{tabular}{lll}
\hline S. No. & Parameters & $\begin{array}{l}\text { USP resolution between } \\
\text { R-isomer and S-isomer }\end{array}$ \\
\hline A. Flow rate & \\
(ml/minutes) & \\
1 & 0.8 & 2.6 \\
2 & 1.0 & 2.4 \\
3 & 1.2 & 2.2 \\
B. Column & & \\
temperature $\left({ }^{\circ} \mathrm{C}\right)$ & & \\
1 & 20 & 2.5 \\
2 & 25 & 2.4 \\
3 & 30 & 2.3 \\
C. Ethanol percentage & & \\
in mobile phase & & \\
1 & 49 & 2.6 \\
2 & 50 & 2.4 \\
3 & 51 & 2.3 \\
\hline
\end{tabular}

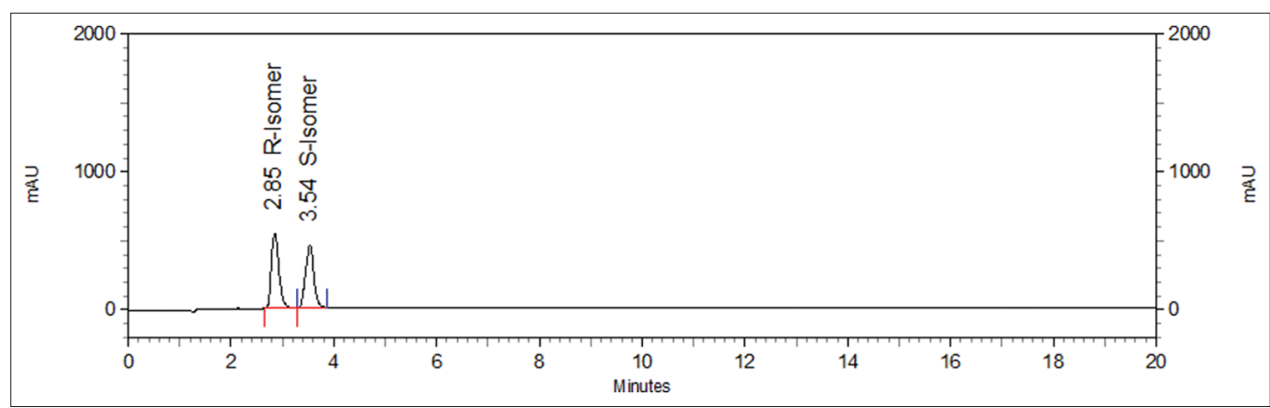

Fig. 4: Typical chromatogram of system suitability standard solution 


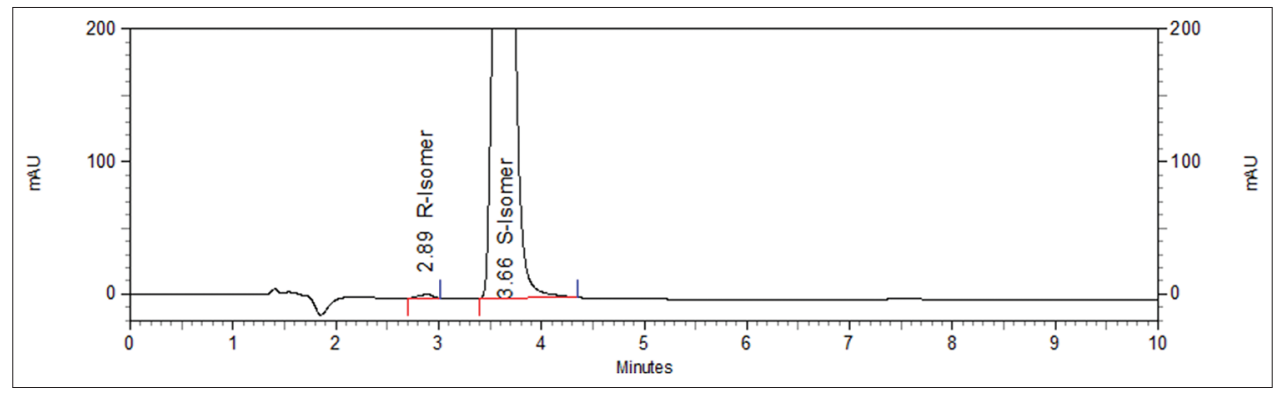

Fig. 5: Typical chromatogram of test solution

and percentage recovery was ranged from 97.4 to 102.0 presented in Table 3 .

An HPLC chromatogram of spiked R-isomer at 0.5\% level in etodolac sample is shown in Fig. 5. The chromatographic resolution of R-isomer and S-isomer of etodolac peaks was used to evaluate the method robustness under modified conditions. The resolution between R-isomer and S-isomer of etodolac was $>2.0$, under all separation conditions tested presented in Table 4.

No significant change in the R-isomer content was observed in etodolac sample during experiments of solution stability and mobile phase stability. Hence etodolac sample solution and mobile phase are stable for at least $48 \mathrm{hrs}$.

\section{CONCLUSION}

A novel, simple, precise, specific, and accurate normal phase liquid chromatography method were described for the separation of etodolac isomer. The method was completely validated as per International Conference on Harmonization guidelines and showing satisfactory data for all the tested method validation parameters. The developed method can be used for the quantitative determination R-isomer in bulk materials.

\section{ACKNOWLEDGMENTS}

We would like to thank management of Lavender Laboratories Pvt Ltd., Kurkumbh, Pune, India for providing the required facilities for completion of this work.

\section{REFERENCES}

1. Jadhav HP, Pathare DB. Enantiomeric separation of etodolac in a bulk drug substance by reverse phase chiral liquid chromatography method. Int J Pharm Pharm Sci 2015;7(7):77-80.

2. Chang CG, Yi HT, Hai HH, Lu SY, Hui DJ, Su Z. Analysis of chira non-steroidal anti-inflammatory drugs flurbiprofen, ketoprofen and etodolac binding with HSA. J Pharm Anal 2011;1(3):184-90.

3. Dung PT, Trung TQ, Kim KH. Preparative resolution of etodolac enantiomers by preferential crystallization method. Arch Pharm Res 2009;32(10):1425-31.

4. Menon S, Kadam N, Gursale A, Gokarn V, Palekar A. A randomized, crossover study to determine bioequivalence of S-etodolac ER tablets versus etodolac ER tablets in healthy Indian subjects. J Appl Res 2009;9(3):57-64.

5. Nishi H, Terabe S. Optical resolution of drug by capillary electrophoretic techniques. J Chromatogr A 1995;69:245-76.

6. IFPMA. Federal register. ICH Draft Guidelines on Validation of Analytical Procedures: Definitions and Terminology. Vol. 60 Switzerland: IFPMA; 1995. p. 11260-2. 